This PDF is a selection from a published volume from the National Bureau of Economic Research

Volume Title: Explorations in the Economics of Aging

Volume Author/Editor: David A. Wise, editor

Volume Publisher: University of Chicago Press

Volume ISBN: 0-226-90337-0

ISBN13: 978-0-226-90337-8

Volume URL: http://www.nber.org/books/wise09-2

Conference Date: May 2009

Publication Date: March 2011

Chapter Title: Is Decentralized Iron Fortification a Feasible Option to Fight Anemia Among the Poorest?

Chapter Authors: Abhijit Banerjee, Esther Duflo, Rachel Glennerster

Chapter URL: http://www.nber.org/chapters/c11948

Chapter pages in book: (317 - 344) 


\title{
Is Decentralized Iron Fortification a Feasible Option to Fight Anemia among the Poorest?
}

\author{
Abhijit Banerjee, Esther Duflo, and Rachel Glennerster
}

\subsection{Introduction}

Iron deficiency is believed to be the most common nutrient deficiency in the world today. While estimating the number of anemic people is difficult, the World Health Organization (WHO) estimates that two billion people are anemic worldwide, and that about half of these cases can be traced to iron deficiency (WHO 2001). Iron deficiency anemia is more common among

Abhijit Banerjee is the Ford Foundation International Professor of Economics and a director of the Abdul Latif Jameel Poverty Action Lab at the Massachusetts Institute of Technology, and a research associate of the National Bureau of Economic Research. Esther Duflo is the Abdul Latif Jameel Professor of Poverty Alleviation and Development Economics and a director of the Abdul Latif Jameel Poverty Action Lab at the Massachusetts Institute of Technology, and a research associate of the National Bureau of Economic Research. Rachel Glennerster is executive director of the Abdul Latif Jameel Poverty Action Lab at the Massachusetts Institute of Technology.

Funding for the evaluation is graciously acknowledged from the Center for Health and Wellbeing at Princeton University (for the baseline survey), the MacArthur Foundation, and the National Institute of Aging. Funding for the intervention was provided by the MacArthur Foundation and the R. D. Tata Trust. We thank Angus Deaton, whose collaboration on the baseline was instrumental in getting this project started, and Amitabh Chandra for useful comments. This project is a collaborative effort involving many people. We particularly thank the team at Seva Mandir, especially Neelima Khetan, CEO, Dr. Sanjana Mohan (the head of the health unit when this project was started, and who was instrumental in designing this project), Bhagirath Gop (coordinator for the fortification project), and Priyanka Singh (head of the health unit when the project was finished). Bruce Daviau played a key role in the design of this program. Specifically, we owe him the design of the mixing machine, but his contribution does not stop there. We thank Hardy Dewan (organisation secretary), Tushita Lodha (project in charge for the health study), and Pramod Tiwari (field coordinator) from Vidya Bhawan for directing and coordinating the data collection. Several research assistants have done spectacular work on the field over the years: Callie Scott, Danielle Li, Vanessa Valentino, Cindy Palladines, Andrew Fraker, Anuja Singh, Payal Sinha, Neil Shah, Dhruva Kothari, and Michael Eddy. Eric Lewis provided expert and incredibly timely data analysis. 
populations with a diet low in animal proteins and high in rice or in whole wheat with high phitates content (phitates reduce absorption). It is therefore a particularly serious issue in Asia and in South Asia. In Indonesia, a large-scale study of iron supplements found that 50 percent of women aged fifteen and above and 40 percent of men sampled were anemic at baseline (Thomas et al. 2003) (using thresholds of $12 \mathrm{~g} / \mathrm{dL}$ and $13 \mathrm{~g} / \mathrm{dL}$ for women and men, respectively).

In our study area, tribal villages in the district of Udaipur in Rajasthan, 80 percent of adult women and 27 percent of adult men out of a sample of 2,519 adults had hemoglobin levels below $12 \mathrm{~g} / \mathrm{dL}$ (Banerjee, Deaton, and Duflo 2004). Fifty one percent of men had hemoglobin levels below $13 \mathrm{~g} / \mathrm{dL}$, the WHO cutoff for anemia for men. Older women were at least as likely to be anemic as younger women, and nutrition was likely a key factor in these high levels of anemia.

Iron deficiency anemia (IDA) has been linked to low productivity in adults and slowing of cognitive and physical growth among children. It increases susceptibility to infection, and increases the likelihood of experiencing weakness or fatigue symptoms (see Haas and Brownlie [2001] for a review of the medical evidence). Among pregnant women, severe anemia can result in low birth weight and child mortality (Stoltzfuz 2001). The medical literature establishes a relationship between iron supplementation and productivity. Iron deficiency affects physical activity by reducing aerobic capacity and by reducing endurance. Few randomized evaluations have looked at the impact of IDA on actual output. Basta et al. (1979) found a large effect of iron supplementation on sugar tree tappers in Indonesia (but the study suffered from fairly large attrition). Li et al. (1994) and Edgerton et al. (1979) found a much smaller effect on productivity, but increased time spent on voluntary activities. The largest and most comprehensive study to date is Thomas et al. (2003), which found a large effect of an iron supplementation program on the labor supply of males who were anemic at baseline, and an increase in the earnings of self-employed males. This study also found reduced anemia, and improved health (including mental health).

While iron deficiency anemia has been recognized as a serious public health problem in developing countries for several years, not much progress has been made against it. Possible interventions to address it include iron supplements (in the form of pills) and supplementation of food. On a large scale, iron supplements are commonly distributed to pregnant women and young children, but males and nonpregnant women are not the focus of regular distribution. Systematic distribution of iron supplements appears to be an unpractical policy in resource poor settings, where the public health systems do not have the capacity to distribute these supplements reliably on a large scale.

Iron supplementation of foods is one alternative: it requires no additional effort on the part of the consumer, and can be done relatively cheaply in 
centralized locations. Foods that can be fortified with iron include flour, milk products, fish sauce, and (recently) salt. The number of countries routinely adding iron to flour increased from two in 1990 to almost fifty in 2004, including countries of Central and South America and the Middle East, plus Indonesia, Nigeria, and South Africa. ${ }^{1}$ Several states in India are now promoting wheat fortification. Gujarat is the leading state for this program. Thirty-five mills produce 40,000 metric tons a month (enough to feed 6.7 million people). Fortifying mills are private, and they receive 50 percent subsidy for iron and folic acid from the state government, and then sell the flour on the open market. West Bengal, Tamil Nadu, Punjab, Andhra Pradesh, and Haryana have smaller, but growing programs. Distribution of fortified flour through the Public Distribution Shops (where those who have a means-test ration card are entitled to buy food at a subsidized price), is now authorized, and Gujarat is piloting it in Ahmadabad, Sabarkantha, and Valsad districts. The government is planning further distribution though school meals programs, hospitals, and other government schemes.

However, for very poor and isolated populations, such as the population in the tribal district of Udaipur where this study was conducted, centralized food fortification is not a practical solution: most households consume their own grain, and do not purchase any goods that could easily be fortified. ${ }^{2}$ Even households who obtain wheat or maize from the Public Distribution system obtain whole grain, which cannot be fortified. Fortification of commercialized food would thus leave marginalized households behind, which would be particularly unfortunate given that they are likely to be the most at risk for IDA.

The only way to reach these households through flour fortification is to fortify flour at the village level. In our study area, households get their grain (maize or wheat) milled once or twice a month by a local miller, or chakki. At this point, the flour can be fortified by mixing it with a preblend of flour and elemental iron, plus vitamin A or folic acid to facilitate absorption. This is a simple operation, which the miller can do immediately after having milled the grain. Community-level fortification is supported by the Micronutrient Initiative (2007), but we were not able to find documentation on other examples. It requires managing considerable logistics, including supplying, training, and monitoring millers in each of the villages. However, the decision to fortify has minimal impact on villagers' behavior. Villagers only have to decide to fortify once, and the nature of milled wheat and maize does not change with fortification. If they experience improvements in their health or in their work capacity, villagers may in turn be willing to pay for

1. According to the Micronutrient Initiative website: http://www.micronutrient.org/english/ view.asp? $\mathrm{x}=579$.

2. With the recent exception of salt. Double fortified salt has recently become available (Micronutrient Initiative 2008) and has shown promising results in field-based randomized control trials. 
such a program. Thus, despite the logistical challenges, community-level (or decentralized) iron fortification is potentially a promising channel to increase iron bio-availability in a consistent and sustained way for the poorest populations. There are, however, many open questions on whether this can be done in a sustainable way: are millers able to fortify regularly, will households demand the service, and how willing are they to pay for it?

This chapter reports on the evaluation of a novel community-level iron supplementation program designed and implemented by Seva Mandir, a nongovernmental organization (NGO) that has worked for over fifty years in tribal areas in the district of Udaipur, Rajasthan. The intervention was implemented in sixty-eight villages, randomly chosen out of 134, where there is a team led by Vidya Bhawan (a local consortium of schools and colleges) and the Abdul Latif Jameel Poverty Action Lab (J-PAL).

A first objective of the evaluation was to assess the logistical feasibility of the intervention: is it possible to recruit, train, and monitor millers and to keep them regularly supplied? Will the population accept the program? A second objective was to determine the impact of the program on anemia. To this end, we collected data on hemoglobin levels at baseline, midline, and end line. The third objective was to determine whether the program had any health effect, beyond a possible reduction in anemia. To achieve this, we collected rich data on health at baseline and end line and a unique monthly health survey, where individuals reported every month on symptoms, selfreported health, and schedule during the past week. The final objective was to assess whether there would be any economic impacts of the program (e.g., increase in work capacity, schooling attendance, etc.).

The results suggest that community-level iron supplementation, when adopted by a substantially large number of people, has the potential to lead to a significant decline of anemia, larger for men than for women (most likely because the dose of iron provided by the program is a lower fraction of the recommended amount for women than for men). However, a troubling finding is that after a rapid ramp up, the take up of the program declined over time in all the regions. In two blocks that took up the program particularly intensively, over 60 percent of the surveyed households were fortifying at the peak and this fell to about 40 percent after the program had been in place for more than a year. In the other three blocks, it fell to about 20 percent at the end of the study period. The consequence is that, in the entire sample, there is no impact of the program on anemia by end line. There is, however, a positive impact of the program on anemia in a midline survey conducted in the two first blocks to start the program after six months and at the end line survey for the two blocks that still had high fortification rates by the end of the program.

Our monthly health monitoring reveals a similar pattern for one of the health symptoms, weakness. Symptoms of weakness declined in the treatment group, relative to the control group in the first six months of the pro- 
gram (when take up was increasing), yet increased again from this low point forward as take-up declined. Other symptoms (diarrhea, vomiting, cough) do not appear to be affected, but it is on weakness that we would expect to see an effect of iron, so this is not surprising. By the end line survey, there appears to be no effect on health (except for self-reported health, happiness, and symptoms of depression for women, but as we argue later there is a good chance that those are reporting or placebo effects).

Finally, there seems to be no impact on the program on the ability to work or the number of days worked. At the end line, the activities of daily living (ADL) scores are similar in treatment and control groups in all blocks, and the ability to do strenuous activities (carry something heavy, climb a hill, walk five kilometers) is no higher, even in the groups with the higher take up. In the continuous monitoring survey, we do not see an increase in days of work, either on average over the period, or concomitant with the ramp up of the program. Of course, they may have been more productive during these days or worked and made more money. Unfortunately we do not have data on this, (collecting income data on a monthly frequency would be impossible), and there is no prima facie evidence that decentralized iron fortification has helped create wealth by improving health. This may explain why the household's willingness to pay for the program, even in the form of a minor inconvenience of walking further to find a chakki that fortifies, is quite low.

The rest of the chapter is organized as follows: section 10.2 describes the context and the detail of the decentralized fortification program. Section 10.3 discusses the identification strategy. Section 10.4 describes the result, and section 10.5 concludes.

\subsection{The Context and Program Details}

\subsubsection{Baseline Descriptive Statistics}

This program took place in Udaipur District, Rajasthan. At the baseline (2002 to 2003), their average per capita household expenditure was 470 rupees, and more than 40 percent of the respondents live in households below the official poverty line (compared with only 13 percent in rural Rajasthan in the latest official counts for 1999 to 2000). Only 46 percent of adult (fourteen and older) males and 11 percent of adult females report themselves as literate. Of the 27 percent of adults with any education, three-quarters completed standard eight or less.

The surveyed households have little in the way of household durable goods and only 21 percent have electricity.

In terms of measures of health, 80 percent of adult women and 27 percent of the adult men had hemoglobin levels below 12 grams by deciliters. Fiftyone percent of adult men had hemoglobin levels below 13, the threshold the 
WHO recommends for men. Five percent of adult women and 1 percent of adult men have hemoglobin levels below 8 grams by deciliters. Using a standard cutoff for anemia ( $12 \mathrm{~g} / \mathrm{dL}$ for women, and $13 \mathrm{~g} / \mathrm{dL}$ for men) 80 percent of adult women and 51 percent of men are anemic. The fact that the rate of anemia is high among men and among older women suggests that diet is a key factor. Indeed, the average body mass index (BMI) is 17.8 among adult men and 18.1 among adult women, which is very low by any standard.

Symptoms of disease are widespread, and adults (self) report a wide range of symptoms: a third reported cold symptoms in the last thirty days, and 12 percent say the condition was serious. Thirty three percent reported fever (14 percent serious); 42 (20) percent reported "body ache"; 23 (7) percent reported fatigue; 14 (3) percent problems with vision; 42 (15) percent headaches; 33 (10) percent back aches; 23 (9) percent upper abdominal pain; 11 (4) percent had chest pains; and 11 (2) percent had experienced weight loss. Few people reported difficulties with personal care, such as bathing, dressing, or eating, but many reported difficulty with the physical activities that are required to earn a living in agriculture. Thirty percent or more would have difficulty walking 5 kilometers, drawing water from a well, or working unaided in the fields. Eighteen to 20 percent have difficulty squatting or standing up from a sitting position.

The baseline data suggest a correlation between anemia status and other measures of health and ability to perform activities of daily living. Those who are anemic have higher ADL scores (indicating more difficulty to perform those difficulties), and lower reported self-reported health, for example. There is also a correlation between anemia and economic well-being. Furthermore, the correlation between anemia and household wealth is stronger for individuals who are earning an income, suggesting that the correlation may go in part from health to earning. However, these correlations remain difficult to interpret without exogenous variations in anemia status. The iron supplementation program provides such exogenous variation.

\subsubsection{Community Iron Fortification Program}

Most of the households in our sample rely on their own production or on whole grain purchased by the Public Distribution System (PDS) for their daily consumption of staples. Specifically, 76 percent of the households never mill their grain at home, and never purchase floor (12 percent sometimes mill at home, and sometimes purchase flour). Wheat and Maize are the main staple foods and they are consumed seasonally in the form of rotis (flat bread made of maize or wheat flour).

The community-level iron program was designed to increase bioavailability of iron for families who do not buy commercial food. The program was designed by Seva Mandir's health unit, headed by Dr. Sanajana Mohan, assisted by Baghirath Mop, in consultation with the Micronutrient Initiative. 
On average, each hamlet has four chakkis (this is also the median number). Three percent of the villages have one chakki, and 20 percent have two. When there was more than one chakki in a hamlet, Seva Mandir chose two participating chakki (thus, not all chakkis participate). Chakkis were offered a flat monthly payment to participate (subsequently the payment was changed to reflect the quantity milled, with bigger chakki getting a large compensation). Chakkis were not chosen randomly, but to serve a maximum number of households. Involving only one chakki per month was a cost-minimizing measure for Seva Mandir (given the fixed cost involved in working with each chakki). It will also give us the opportunity to examine the willingness of households to switch to (or away from) a participating chakki.

This fortification program had two objectives: to supply a sufficient quantity of iron in the diet, and to avoid supplying too much iron. Safety was also a concern, as the process was not as tightly monitored as it would have been in a factory. It was important that the program was robust to accidental over fortification.

The technology for fortification begins with a premix, a dry powdered mix with specific concentrations of one or more micronutrients. This premix is diluted into a preblend (because premix is too concentrated to be properly hand-mixed into the flour) and then added to flour either (a) during the milling process, or (b) after the grain has been milled.

Elemental iron is available in different forms (reduced iron, ferrous sulphate, or ferrous fumerate). After consultations with micronutrient initiatives and various experts, Seva Mandir chose to use ferrous sulfate (FeSO4) and folic acid (which helps with iron absorption). This premix was then mixed with flour at Seva Mandir (16.66 g of premix is added in $1 \mathrm{~kg}$ of flour), to produce a preblend that had $3300 \mathrm{ppm}$ (or milligram per kilo) of elemental iron (as ferrous sulfate). This quantity is sufficiently diluted, so that if someone were to eat the preblend without mixing, there would be no health risk.

This preblend was then mixed with the ground grain (maize of wheat) using the following procedure. Customers bring their whole grains to the chakki in bags, boxes, or baskets. First, the chakki empties this into his own milling machine, which grinds the grains into flour, and weighs the resulting flour (chakki charge by weight, so they all have scales for weighing flours). Second, he transfers the flour into a separate mixing machine (see appendix, figure 10A.1 for a picture of the milling machine, which was designed for Seva Mandir by Canadian engineer Bruce Daviau), and adds the required amount of preblends using a $30 \mathrm{~g}$ scoop that was provided by Seva Mandir. A scoop thus contains $100 \mathrm{mg}$ of iron. The number of scoops to be added corresponds to table 10.1. He then turns the handle of the mixing machine ten times in one direction, and ten times in the other, and gives the fortified flour to the customer. He does not charge the customer for the extra supplement. 
Table 10.1

Amount of preblends

\begin{tabular}{cc}
\hline Kg of flours & Number of scoops \\
\hline $3-5.99$ & 1 \\
$6-8.99$ & 2 \\
$9-11.99$ & 3 \\
$12-14.99$ & 4 \\
$15-18$ & 5 \\
\hline
\end{tabular}

The final concentration of iron in the flour thus ranges from about 20 to $33 \mathrm{mg}$ per kilogram (except for the top of the first bin). A pilot survey on the kilograms of flour milled showed that the average adult eats $.3 \mathrm{~kg}$ of flour per day. This implies that the average adult would get an extra 6 to $12 \mathrm{mg}$ from the fortified flour. The WHO provides recommended iron intakes for populations with very low dietary intake of iron. For adult males the WHO recommends $27.4 \mathrm{mg} /$ day. For adult, nonmenopausal females, this number is $58.8 \mathrm{mg} /$ day. Thus, the program provides between 20 and 40 percent of the Recommended Daily Intake (RDI) in iron for males, and 10 to 20 percent for females. We should thus expect a larger effect on reduction in anemia for males, especially as they presumably eat more than women and thus absorb more than the average. In practice, intervention monitoring suggests that households consume on average $400 \mathrm{~g}$ of flour per day, which increases slightly the anticipated iron intake of a fortifying family.

The participating chakkis, their employees, and all their family members involved in their business, were trained by Seva Mandir in these procedures. Chakkis were initially given a flat fee to participate in the program, independent of the volume of their business or the number of households who fortified. ${ }^{3}$ Chakkis were instructed to keep logbooks where they indicated how much grain had been milled, and whether or not they had fortified.

Seva Mandir put in place a system of monitoring of the chakki, which was implemented by the research team at Vidya Bhawan. About once a month, a field officer visited each chakki, inspected the log book, performed a spot test of fortified flour at the chakki, and randomly visited a few families who had fortified recently to perform a spot test at their house. The spot test is semiquantitative: it indicates the presence of iron in the flour, but it cannot indicate how much there was.

Before the program was started in a village, a village meeting took place, where the cause and consequences of iron deficiency anemia were discussed, as well as what households could do to prevent it (changes in diet, etc.). The program was then explained to the village, and the village collectively agreed to participate (all villages agreed). To avoid creating spurious effects due to

3. Later on, the payment was made contingent on the chakki's size, to compensate him for the large amount of extra work involved. 
the information regarding anemia, Seva Mandir held a village meeting in control villages as well, where the discussion was the same (except that the program was not discussed). Each village had participating and nonparticipating chakkis. At the individual level, a household had to initially agree to be a participant. Once a household had accepted the program once, the chakki were to consider them to be participating households, unless they explicitly declined fortification. However, in spite of the initial decision to fortify, many households did not regularly fortify, either because the chakki did not always fortify the grain, or because households switched to nonparticipating chakkis.

Monitoring revealed some implementation challenges. Chakkis did not keep good records (many are illiterate), and seem to not have followed the instruction to continue to fortify flour for a household if they had initially decided to participate. On one key dimension, the program appears to have been consistently well-implemented, however: most of the spot checks do reveal the presence of iron among households chosen among those who had fortified. The household visit was also the occasion to collect information on any possible side effects or issue. There were essentially no side effects or complaints, except for a few complaints that the roti (flat bread) sometimes became black when on the fire. To our knowledge, this occasionally happens, and the fact that the flour is fortified does not increase the likelihood of this event.

\subsection{Evaluation Design and Data Collection}

This research is a collaborative undertaking of Seva Mandir (the organization that designed and implemented the decentralized iron fortification program), Vidya Bhawan (a consortium of schools and colleges who undertook the data collection), and a team from MIT led by the authors of this chapter.

Ethical approval for this project and the study was obtained from MIT, the human subject committee at Vidya Bhawan, Udaipur, and the Indian Council of Medical Research.

One hundred and thirty four "hamlets" were part of the study. The sample was stratified according to access to a road (out of the 134 hamlets, half of them are at least 500 meters away from a road). Hamlets within each stratum were selected randomly, with a probability of being selected proportional to the hamlet population. A baseline survey of ten households in each of 100 hamlets was conducted in 2002 and 2003. In 2004 and 2005, twenty additional households were surveyed in each hamlet, and thirty-four hamlets were added to the sample.

Out of these 134 hamlets, 65 were randomly selected (by the research team, using the random generator in Stata) to received the iron fortification program. The randomization was done after stratification by block (a 
block is an administrative area, below the district, and also an administrative unit for Seva Mandir), and by the randomization status for two other interventions that were conducted and evaluated in the same villages (a nurse absenteeism study, and an immunization incentive program). The program started in a staggered fashion by block: after an initial pilot in four villages, it started in the first two blocks (Bargaon and Girwa) in January 2006. It then was introduced in Jadhol in June 2006, in Kotra in October 2006, and in Kherwara in November 2006.

An end line survey was conducted between July 2007 and March 2009. All the individuals surveyed at baseline in all the households were attempted to be surveyed at end line. Almost all households (96 percent) were found. At the individual level, the attrition is 19 percent. Attrition is mainly due to seasonal migrants, who could not be traced back to the village.

The baseline and end line survey data include a detailed household module (including information about consumption, assets, etc.). For households in treatment villages, we also have information specific to fortification (which chakki they normally use, whether the chakki they use fortifies flour, whether they choose to fortify, and if not, why not), and an individual module, which includes, among other things, information about working hours for the past week, and a detailed interview on health-seeking behavior. The individual module also includes health and mental health information: self-reported conditions experienced in the past thirty days, self-reported health status, self-reported happiness, and a depression module. Finally, basic health measurements are obtained: health, weight, blood pressure, peak flow meter, and hemoglobin.

Hemoglobin was measured using hemocue machines. The respondent's finger is pricked with a lancet, and the second drop of blood is put in a cuvette, which is inserted in the machine, which provides an immediate reading. In what follows, we adopt the following threshold from the World Health Organization ${ }^{4}$ to determine "anemia": a hemoglobin level below 12 is considered to be anemic for nonpregnant women (11 for pregnant women), and a hemoglobin level below 13 is considered to be anemic for men.

In addition to the baseline and end line survey, several other data sets were collected for the analysis. First, we have data from the spot checks conducted to monitor program implementation (availability of iron in the flour at the chakki, and availability of iron in the flour of the households who were reported to have recently fortified their flour). We also have information on the location of all the chakkis in the village.

Second, we have collected a unique data set: the continuous household survey (CHS). This data set is a short survey, performed every month. One local person (a paraworker) was hired to conduct this survey every month among the thirty households in the villages. The survey included questions 
on symptoms experienced by household members over the last thirty days (including vomiting, diarrhea, and weakness), days spent doing different activities (work for pay, work in the field, tending the animals, school, etc.) over the last week, and visits to different health facilities over the last month. The individual questions were to be asked directly to the individual. A few months after the program started in the first two blocks, a question was added asking how many times the household had milled grain in the past month, and whether or not they had fortified the flour.

A monitor visited the paraworker regularly (about once a month) to check that the surveys were properly filled, and accompanied the paraworker during the household visit that day for on-the-job training. There are 841,057 observations (individual-month) for a panel of about 4,000 households, spanning over two years. While the data is certainly not as good as a panel collected by a professional supervisor may be (and we still need to more work to validate it), it is a useful data source for other purposes.

\subsection{Results}

\subsubsection{Program Take up}

Figure 10.1 shows the fraction of households fortifying their flour at least once in the past month (according to their self-report in the continuous household surveys, which introduced the question a few months after the program started in the first regions), and figure 10.2 shows the fraction of times when they were fortifying their flour in the past month (out of the num-

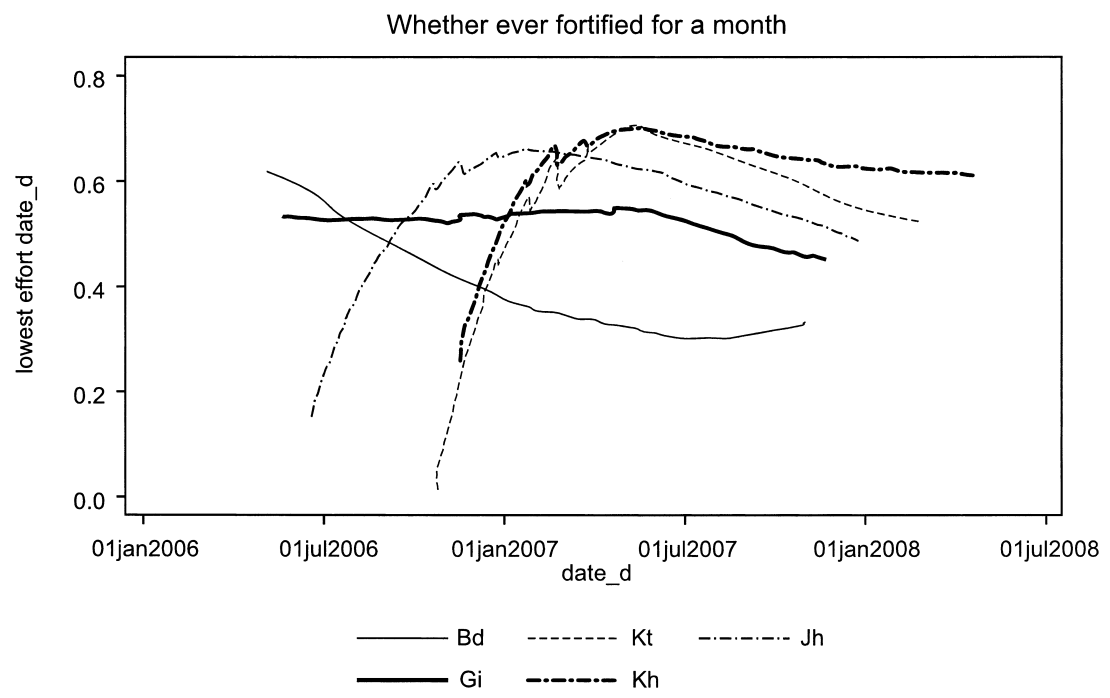

Fig. 10.1 Whether ever fortified for month 


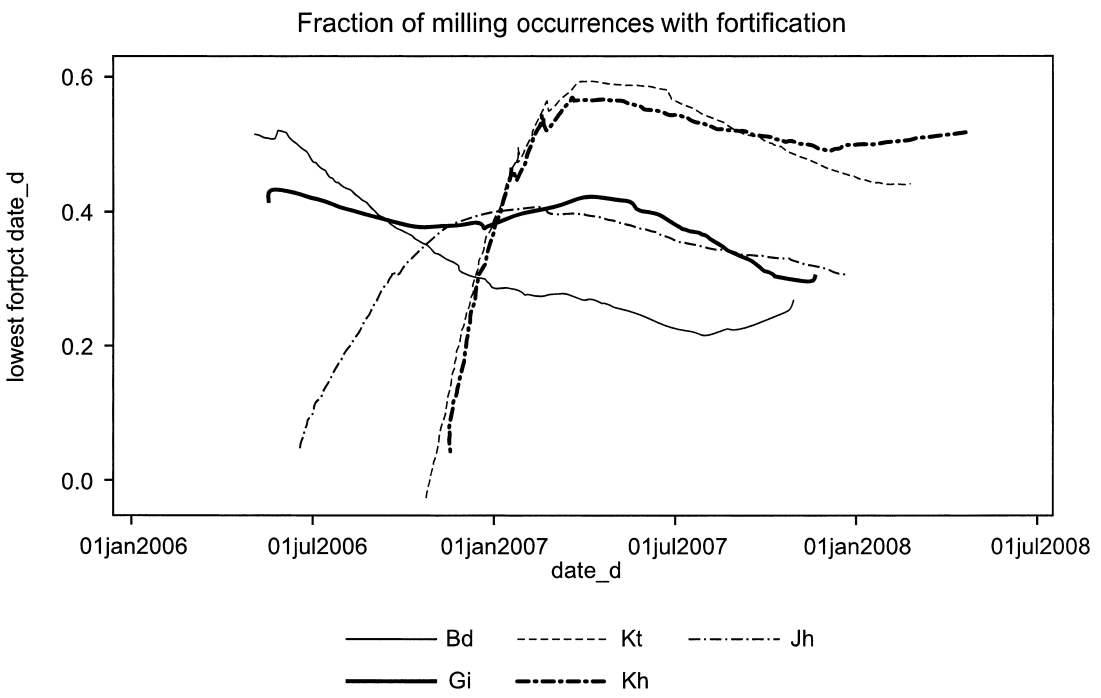

Fig. 10.2 Fraction of milling occurrences with fortification

ber of times they actually milled flour), in the different administrative blocks where Seva Mandir is operating. Unfortunately, the fortification question was introduced with some delay in the CHS: we do not have the beginning of the program for the first two blocks to start (Girwa and Bagdaon).

Both figures show that take up varied across regions, with the two blocks that started later having consistently higher take up. They show very sharp time trend in the take up of the program: at the beginning, take up increases quickly. Following a peak about six months after the program was introduced, there is a strong decline in the take up of the program by households over time in all regions. Table 10.2, panel A, shows a regression of take up on a spline function of date since introduction, for the first six months of the program, and for the following six months, and shows that those trends are strongly significant.

Table 10.2, panel B, shows the fraction of household that fortified, and the fraction of time they fortified, over the entire period the program was in activity in the region, and over the last three months before the end line survey. By the time the end line survey took place, very few households were fortifying their flour in three of the blocks, while two had fortification rates above 50 percent.

Some insight on why the take up declined is provided by figure 10.3. Figure 10.3 plots the take up of the program as a function of the date the program started for all the blocks together, and separates the households into three groups: those for whom the closest chakki fortifies; those who do not fortify, but have a fortifying chakki nearby (within 1.5 kilometers for this specifica- 
Take up of the program

\begin{tabular}{|c|c|c|c|c|}
\hline \multicolumn{5}{|c|}{ A Take up over time } \\
\hline & \multicolumn{2}{|c|}{$\begin{array}{l}\text { no. of households who } \\
\text { fortify }\end{array}$} & & \\
\hline Spline: Slope all months & $\begin{array}{c}0.0645 \\
(0.0081)\end{array}$ & $\begin{array}{c}0.0694 \\
(0.0087)\end{array}$ & & \\
\hline Spline: Slope for months 7-end & $\begin{array}{l}-0.0854 \\
(0.0095)\end{array}$ & $\begin{array}{c}-0.0863 \\
(0.0096)\end{array}$ & & \\
\hline Average take up first 6 months & 0.5639 & & & \\
\hline Block fixed effects & $\mathrm{N}$ & $\mathrm{Y}$ & & \\
\hline \multicolumn{5}{|c|}{ B Average take up } \\
\hline & \multicolumn{2}{|c|}{ Entire period } & \multicolumn{2}{|c|}{$\begin{array}{l}\text { Last } 3 \text { months before } \\
\text { end line }\end{array}$} \\
\hline & $\begin{array}{l}\text { Fortified } \\
\text { last month }\end{array}$ & $\begin{array}{l}\% \text { time } \\
\text { fortified }\end{array}$ & $\begin{array}{l}\text { Fortified } \\
\text { last month }\end{array}$ & $\begin{array}{l}\% \text { time } \\
\text { fortified }\end{array}$ \\
\hline Badgaon & 0.31 & 0.39 & 0.20 & 0.28 \\
\hline Kotra & 0.47 & 0.58 & 0.42 & 0.54 \\
\hline Girwa & 0.41 & 0.57 & 0.30 & 0.48 \\
\hline Kherwara & 0.50 & 0.64 & 0.43 & 0.56 \\
\hline Jhadol & 0.35 & 0.52 & 0.29 & 0.43 \\
\hline All blocks & 0.41 & 0.54 & 0.33 & 0.45 \\
\hline
\end{tabular}

tion, but the findings are robust to other distance); and those who do not have a fortifying chakki within 1.5 kilometers (which does happen, given that Udaipur district is very sparsely populated). Take up initially increases in all three groups, but does not reach the same peak for those who do not have a chakki nearby. All those who have a chakki nearby reach the same peak, but take up falls down more quickly for those for whom it is not the closest one, presumably because households switched back to their normal chakki after a while.

\subsubsection{Impact on Anemia and Hemoglobin Levels}

\section{Attrition}

One unfortunate limitation in our ability to detect any impact of the program on anemia is that while overall attrition in the survey is fairly low, attrition in hemoglobin measurement is much higher, and is significantly different in treatment and control groups (see table 10.3).

This is primarily due to a combination of dysfunctional hemocue machines (about two-thirds of the cases among adults) and refusals (about one-third among adults). While the interviewing team spent considerable time 


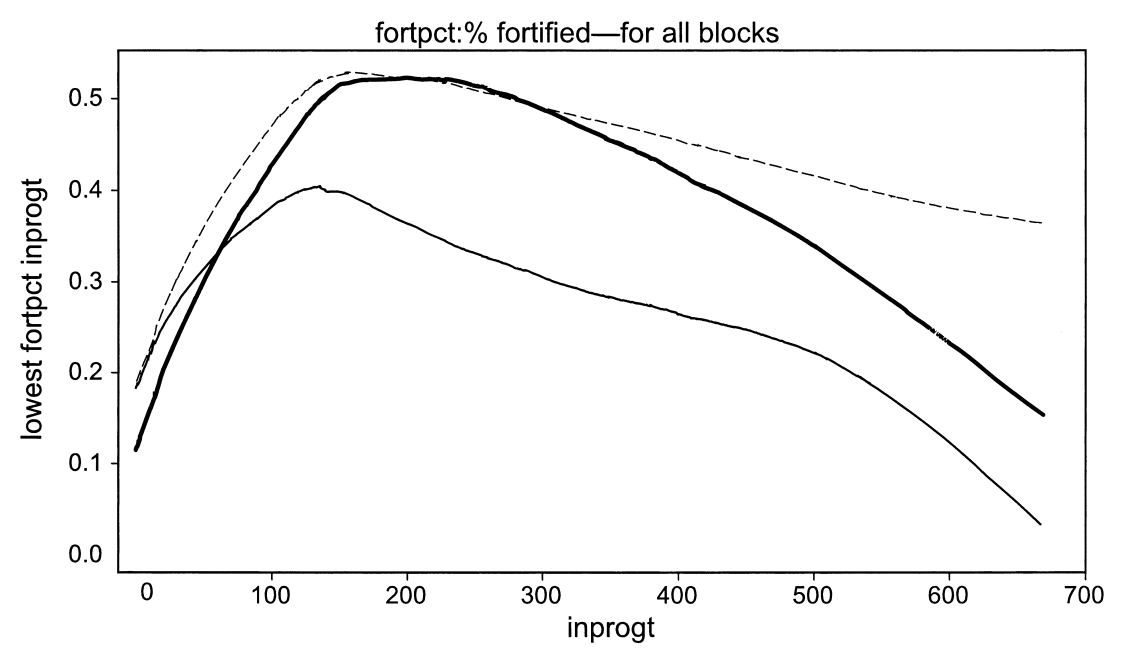

closest chakki is treatment

nearby chakki is treatment

no treatment chakki nearby

Fig. 10.3 Percentage fortified for all blocks

tracking down households and individuals, for ethical reasons, interviewers were instructed to address any concerns over safety, use of the blood, or confidentiality, but not to insist beyond this if individuals still refused the blood prick. ${ }^{5}$ Refusals are particularly high among children: in the control group, only 20 percent of the children age zero to five who are in the end line survey have a valid hemocue measurement, and only 55 percent of the children aged five to fourteen have a valid hemocue measurement. Among adults, in the control group, 36 percent of those who are otherwise present in the end line do not have valid hemoglobin data.

Attrition does not appear to be random. First, it is lower in the treatment group than in the control group by about 6 percentage points for adults. Second, those for whom we have end line data on other variables but no anemia data tend to be older, skinnier, and more likely to be anemic at baseline (table 10.4). Since the anemia test involved a blood prick, refusals are more frequent when people are weak (or for young children), often because respondents feared that the test might make them even weaker. In villages where iron was distributed, it appears that interviewers were more likely to be able to convince respondents to be subject themselves to the blood prick,

5. Interviewers generally come from a much higher social background than respondents, and the line between persuasion and undue influence could have been quite fine if interviewers were requested to insist on the test. 
Table 10.3 Attrition

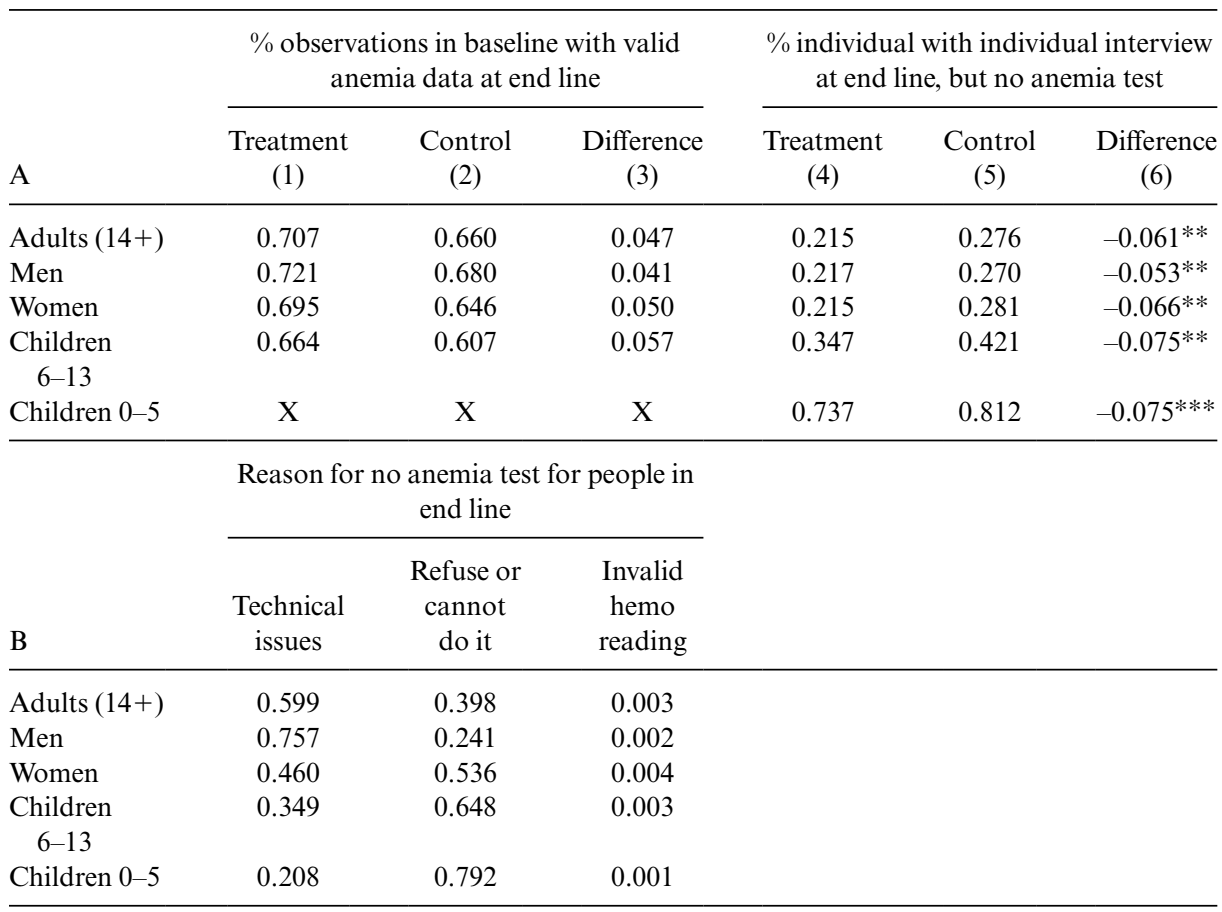

Note: $\mathrm{X}$ indicates not surveyed.

perhaps because respondents were grateful for the program, and happy to cooperate to its evaluation. The likely effect of attrition is to lead to underestimate the impact of the program on anemia, since the extra observations in the treatment groups are drawn from a weaker group.

\section{Impacts: Reduced Forms}

Despite this shortcoming of the hemoglobin data, we examine the impact of the program on hemoglobin level and anemia. Given the very high rates of attrition among children, we focus on adults.

The analysis is conducted with a simple linear regression, in the sample of individuals aged fourteen or higher at the end line, and who are present in the baseline:

$$
y_{i j}=\alpha+\beta T_{j}+X \gamma+\varepsilon_{i j},
$$

where $y$ is the outcome of interest, $T$ is a dummy indicating whether the household was in a treated village, and $X$ are control variables. The standard errors are adjusted for heteroskedasticity and clustering at the village level using White standard errors. All the regressions are weighted by the inverse of the probability of selection of the village in the overall sample. 
Attrition: Difference between attritors and nonattritors for selected characteristics

\begin{tabular}{|c|c|c|c|c|c|c|}
\hline & \multicolumn{3}{|c|}{ Age } & \multicolumn{3}{|c|}{ BMI } \\
\hline & $\begin{array}{l}\text { Treatment } \\
\text { (1) }\end{array}$ & $\begin{array}{l}\text { Control } \\
\text { (2) }\end{array}$ & $\begin{array}{l}\text { Difference } \\
\text { (3) }\end{array}$ & $\begin{array}{l}\text { Treatment } \\
\text { (4) }\end{array}$ & $\begin{array}{l}\text { Control } \\
\text { (5) }\end{array}$ & $\begin{array}{l}\text { Difference } \\
\text { (6) }\end{array}$ \\
\hline In end line survey & 36.6 & 36.7 & $\begin{array}{l}-0.125 \\
(0.661)\end{array}$ & 17.999 & 18.044 & $\begin{array}{l}-0.045 \\
(0.181)\end{array}$ \\
\hline $\begin{array}{l}\text { Not in end line } \\
\text { survey }\end{array}$ & 37.2 & 36.0 & $\begin{array}{c}1.109 \\
(5.867)\end{array}$ & 17.917 & 17.296 & $\begin{array}{c}0.621 \\
(0.674)\end{array}$ \\
\hline $\begin{array}{l}\text { In end line survey } \\
\text { with anemia } \\
\text { data }\end{array}$ & 36.7 & 36.7 & $\begin{array}{l}-0.063 \\
(0.694)\end{array}$ & 18.025 & 18.019 & $\begin{array}{c}0.006 \\
(0.191)\end{array}$ \\
\hline \multirow[t]{3}{*}{$\begin{array}{r}\text { In end line survey } \\
\text { no anemia data }\end{array}$} & 36.2 & 36.6 & $\begin{array}{l}-0.310 \\
(1.310)\end{array}$ & 17.932 & 18.099 & $\begin{array}{l}-0.167 \\
(0.245)\end{array}$ \\
\hline & \multicolumn{3}{|c|}{ Hemocue at baseline } & \multicolumn{3}{|c|}{ Self-reported health } \\
\hline & $\begin{array}{l}\text { Treatment } \\
\text { (7) }\end{array}$ & $\begin{array}{l}\text { Control } \\
\text { (8) }\end{array}$ & $\begin{array}{l}\text { Difference } \\
\quad(9)\end{array}$ & $\begin{array}{l}\text { Treatment } \\
\text { (10) }\end{array}$ & $\begin{array}{l}\text { Control } \\
\text { (11) }\end{array}$ & $\begin{array}{l}\text { Difference } \\
\text { (12) }\end{array}$ \\
\hline In end line survey & 11.702 & 11.605 & $\begin{array}{c}0.097 \\
(0.123)\end{array}$ & 5.929 & 5.858 & $\begin{array}{c}0.071 \\
(0.144)\end{array}$ \\
\hline $\begin{array}{l}\text { Not in end line } \\
\text { survey }\end{array}$ & 11.362 & 11.883 & $\begin{array}{l}-0.521 \\
(0.438)\end{array}$ & 5.972 & 6.332 & $\begin{array}{l}-0.359 \\
(0.682)\end{array}$ \\
\hline $\begin{array}{l}\text { In end line survey } \\
\text { with anemia } \\
\text { data }\end{array}$ & 11.709 & 11.721 & $\begin{array}{l}-0.011 \\
(0.123)\end{array}$ & 5.855 & 5.803 & $\begin{array}{c}0.052 \\
(0.156)\end{array}$ \\
\hline $\begin{array}{l}\text { In end line survey } \\
\text { no anemia data }\end{array}$ & 11.681 & 11.348 & $\begin{array}{c}0.332 \\
(0.209)\end{array}$ & 6.121 & 5.980 & $\begin{array}{c}0.141 \\
(0.236)\end{array}$ \\
\hline
\end{tabular}

In the basic specification, $X$ only contains dummies for blocks' age, age squared, and gender (unless the analysis is separated by gender). We also include a specification where we control for baseline hemoglobin level (observations without hemoglobin status are included, as well as a dummy for "missing hemoglobin status").

The results are presented in table 10.5, panel A, for the overall sample. There appears to be no detectable difference in hemoglobin or in the prevalence of anemia between the treated and the control groups for women. For men, there is a 4 percentage point reduction in anemia, significant at the 10 percent level when we control for baseline anemia. (However, surprisingly the reduction in anemia between treatment and control groups is no higher for those who were anemic at baseline.)

While these estimates are indicative of the (lack of) effect of the fortification program in the entire sample after eighteen months to two years of existence, they may reflect in part the very low take up of the program toward its end, at least in three of the blocks where it had been operating for a long time. The question of whether the fortification program could reduce anemia if take up were higher is therefore of independent interest. 


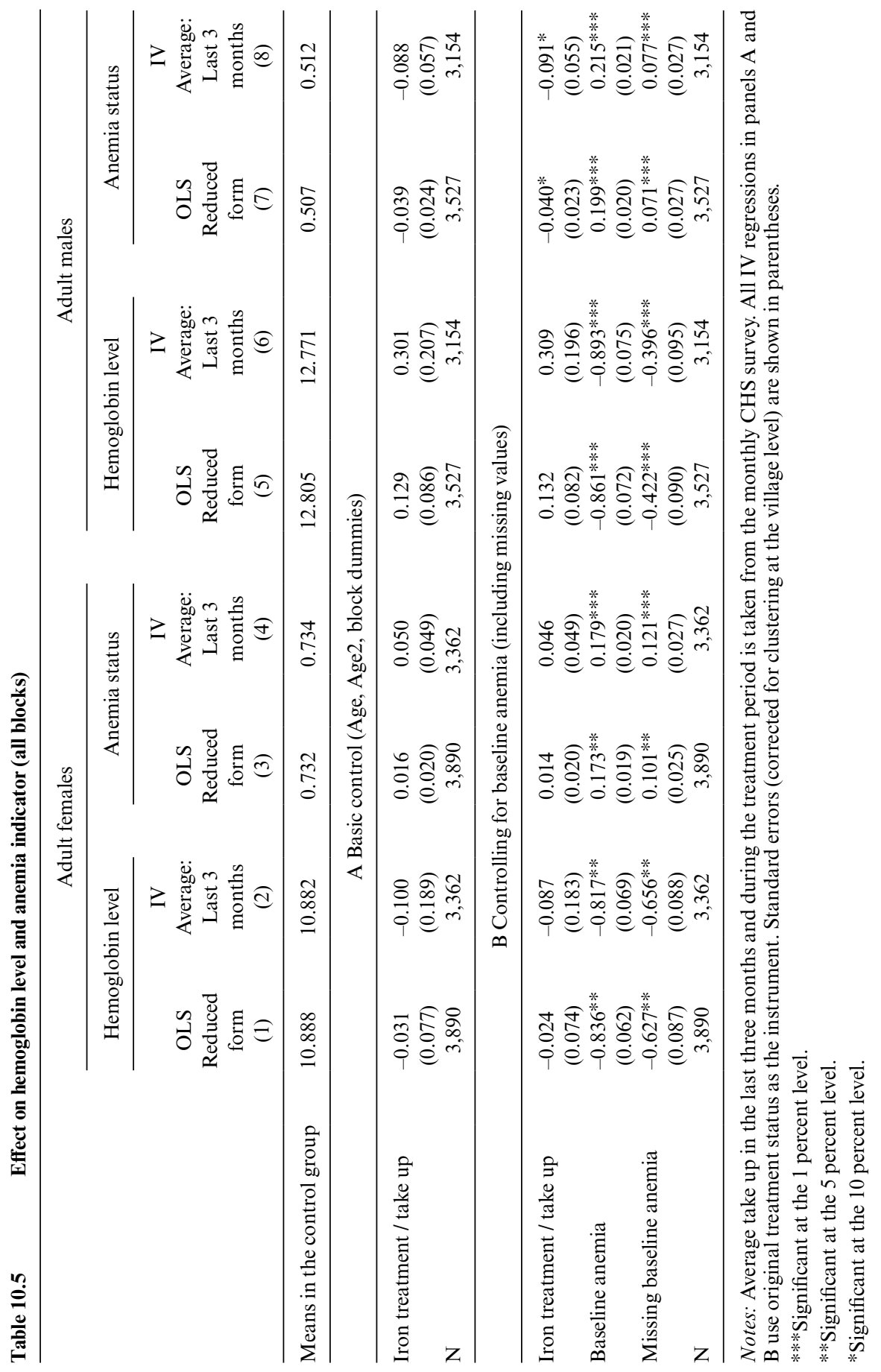


Midline effect on hemoglobin level and anemia indice (Girwa and Bargaon)

\begin{tabular}{|c|c|c|c|c|c|c|}
\hline & \multicolumn{6}{|c|}{ Adults only } \\
\hline & \multicolumn{3}{|c|}{ Hemoglobin level } & \multicolumn{3}{|c|}{ Anemic } \\
\hline & $\begin{array}{l}\text { All } \\
\text { (1) }\end{array}$ & $\begin{array}{l}\text { Female } \\
\text { (2) }\end{array}$ & Male & $\begin{array}{l}\text { All } \\
(3)\end{array}$ & $\begin{array}{c}\text { Female } \\
\text { (4) }\end{array}$ & Male \\
\hline $\begin{array}{l}\text { Means in the } \\
\text { control group }\end{array}$ & 11.466 & 10.717 & 12.416 & 0.706 & 0.789 & 0.601 \\
\hline \multicolumn{7}{|c|}{ Basic control (Age, Age2, block dummies) } \\
\hline Iron treatment & $\begin{array}{c}0.299 \\
(0.183)\end{array}$ & $\begin{array}{l}0.308^{* *} \\
(0.149)\end{array}$ & $\begin{array}{c}0.298 \\
(0.288)\end{array}$ & $\begin{array}{l}-0.071^{*} \\
(0.040)\end{array}$ & $\begin{array}{c}-0.077 * * \\
(0.037)\end{array}$ & $\begin{array}{c}-0.065 \\
(0.059)\end{array}$ \\
\hline $\mathrm{N}$ & 2,253 & 1,324 & 929 & 2,253 & 1,324 & 929 \\
\hline \multicolumn{7}{|c|}{ Basic controls plus control for baseline anemia status } \\
\hline Iron treatment & $\begin{array}{c}0.274 \\
(0.179)\end{array}$ & $\begin{array}{c}0.233 \\
(0.154)\end{array}$ & $\begin{array}{c}0.335 \\
(0.292)\end{array}$ & $\begin{array}{l}-0.068^{* *} \\
(0.034)\end{array}$ & $\begin{array}{l}-0.075^{* *} \\
(0.031)\end{array}$ & $\begin{array}{c}-0.059 \\
(0.056)\end{array}$ \\
\hline $\mathrm{N}$ & 1,439 & 851 & 588 & 1,439 & 851 & 588 \\
\hline
\end{tabular}

**Significant at the 5 percent level.

* Significant at the 10 percent level.

A midline survey, which was realized in two blocks that started the program first (Girwa and Bargaon) sheds more light on this question: the midline was conducted there a year after the program started, when the take up in those blocks was still high. Table 10.6 shows the impact of the treatment on anemia in these two blocks at midline. It shows a significant difference in anemia rate of about 7 percentage points between treatment and control villages. The effects are larger than at the end line, are are now similar for men and for women. The difference is due to the timing of the survey (when the take up was high) and not to the fact that the program effects are somehow larger in Girwa and Bargaon: to the contrary, when we separate the results by blocks, the endline anemia differences are highest in Kotra and Kerwara, the two blocks where take up was highest by the end line (results omitted to save space).

To sum up, flour fortification appears to be associated with a decline in the rate of anemia as long as a sufficient number of people take it up. But take up of the program was not sustained, which eventually made it largely ineffective. This suggests a potentially large impact of the iron supplementation itself on anemia, combined with a relatively low take up.

\section{Impacts of Iron Supplementation on Anemia} Status Instrumental Variable Specification

To estimate the effect of the supplementation program, we estimate an instrumental variable specification. In equation (1), $T_{i j}$ is replaced by variables indicating the fraction of times in the last three months that a house- 
hold has fortified their flour $\left(F_{i j}\right)$. This equation is then estimated with twostage least squares, $T_{i}$, serving as the instrument for $F_{i j}$.

The results are presented in the even columns in table 10.5. Not surprisingly, since the first stage is the same for men and women (since it is defined as the household basis), we find the same conclusion that, at the end line, iron supplementation seems to have significant impacts only for men. The implied effects are fairly large: regular iron supplementation over the last three months would lead to a reduction of 9 percentage points in the incidence of anemia among men, a 17 percent decrease. It should be noted that the instrumental variable (IV) estimate gives us the effect for those who chose to fortify, and thus who may have experienced the largest effect.

\subsubsection{Impacts on Health and Work Outcomes}

Table 10.7 shows the impact on health at the end line survey. In the entire sample, women in villages that received the program have significantly higher BMI, higher self-reported health, higher self-reported happiness, and are less likely to be depressed. There is no impact on symptoms reported, ADL score, or their ability to carry strenuous activity. The results go in the same direction for men (with the exception of the ability to climb a hill, which appears to be lower in the treatment group), but are all insignificant. When we look at the results separately for the high fortification and low fortification blocks, the results (omitted to save space) are very similar in both types of blocks.

The fact that the results are higher for women than for men, and high in all blocks irrespective of the take up by end line (and thus the effect on anemia by end line), suggests that there may be a reporting bias in the selfreported measures, with women ready to report themselves in better health to be polite to the investigators.

The continuous household survey is the ideal data set to look at the impact of the program on conditions experienced by each individual, self-reported health, and activities, since we have one data point per household every month. We can look at the impact of the program during the entire time it was in place (rather than just at the very end, when take up was low), as well as look at how the impact varies over time. It is also less likely that households would differentially report their health in treated and control villages, since they are reporting this information to a village member, not to an outside surveyor, and they are reporting every week. The symptoms reported in the continuous household survey are diarrhea, vomiting, weakness, and "other." Anemia should primarily affect weakness, which is therefore our main symptom of interest. Diarrhea and vomiting are also of interest, since they are possible side effects of iron supplementation. We also examine the impact of the project on self-reported health and days of work activity over the last week (these aggregate several possible work activities: work in the field, work for a wage, tending animals, etc.).

For each outcome $y_{i j t}$, we present the following specifications: 


\begin{tabular}{|c|c|c|c|c|}
\hline & \multicolumn{2}{|c|}{ Females } & \multicolumn{2}{|c|}{ Males } \\
\hline & $\begin{array}{l}\text { OLS } \\
\text { Reduced } \\
\text { form } \\
\quad(5)\end{array}$ & $\begin{array}{c}\text { IV } \\
\text { Average: } \\
\text { Last } 3 \\
\text { months } \\
\text { (7) }\end{array}$ & $\begin{array}{l}\text { OLS } \\
\text { Reduced } \\
\text { form } \\
\text { (9) }\end{array}$ & $\begin{array}{c}\text { IV } \\
\text { Average: } \\
\text { Last } 3 \\
\text { months } \\
\text { (11) }\end{array}$ \\
\hline BMI & $\begin{array}{c}0.241^{*} \\
(0.132)\end{array}$ & $\begin{array}{c}0.521 \\
(0.317)\end{array}$ & $\begin{array}{c}0.172 \\
(0.113)\end{array}$ & $\begin{array}{c}0.391 \\
(0.267)\end{array}$ \\
\hline Self-reported health & $\begin{array}{c}0.165^{*} \\
(0.097)\end{array}$ & $\begin{array}{l}0.450 * * \\
(0.223)\end{array}$ & $\begin{array}{c}0.088 \\
(0.094)\end{array}$ & $\begin{array}{c}0.192 \\
(0.222)\end{array}$ \\
\hline Cold & $\begin{array}{c}-0.004 \\
(0.018)\end{array}$ & $\begin{array}{c}-0.006 \\
(0.042)\end{array}$ & $\begin{array}{c}0.005 \\
(0.019)\end{array}$ & $\begin{array}{c}0.006 \\
(0.043)\end{array}$ \\
\hline Any kind of cough & $\begin{array}{c}-0.010 \\
(0.017)\end{array}$ & $\begin{array}{c}-0.009 \\
(0.040)\end{array}$ & $\begin{array}{c}-0.017 \\
(0.017)\end{array}$ & $\begin{array}{c}-0.046 \\
(0.039)\end{array}$ \\
\hline Fever & $\begin{array}{c}-0.019 \\
(0.017)\end{array}$ & $\begin{array}{c}-0.038 \\
(0.038)\end{array}$ & $\begin{array}{c}0.014 \\
(0.016)\end{array}$ & $\begin{array}{c}0.032 \\
(0.039)\end{array}$ \\
\hline Weakness & $\begin{array}{c}-0.028 \\
(0.018)\end{array}$ & $\begin{array}{c}-0.054 \\
(0.042)\end{array}$ & $\begin{array}{c}0.011 \\
(0.016)\end{array}$ & $\begin{array}{c}0.015 \\
(0.038)\end{array}$ \\
\hline Body ache & $\begin{array}{c}0.000 \\
(0.014)\end{array}$ & $\begin{array}{c}0.013 \\
(0.033)\end{array}$ & $\begin{array}{c}0.022 \\
(0.015)\end{array}$ & $\begin{array}{c}0.045 \\
(0.034)\end{array}$ \\
\hline Vomiting & $\begin{array}{c}-0.010 \\
(0.009)\end{array}$ & $\begin{array}{c}-0.015 \\
(0.022)\end{array}$ & $\begin{array}{l}0.019^{* * *} \\
(0.007)\end{array}$ & $\begin{array}{l}0.039 * * \\
(0.018)\end{array}$ \\
\hline Diarrhea & $\begin{array}{c}-0.001 \\
(0.010)\end{array}$ & $\begin{array}{c}0.000 \\
(0.024)\end{array}$ & $\begin{array}{c}0.007 \\
(0.009)\end{array}$ & $\begin{array}{c}0.018 \\
(0.024)\end{array}$ \\
\hline Self-reported happiness & $\begin{array}{c}0.076^{*} \\
(0.042)\end{array}$ & $\begin{array}{c}0.139 \\
(0.095)\end{array}$ & $\begin{array}{c}0.032 \\
(0.041)\end{array}$ & $\begin{array}{c}0.075 \\
(0.093)\end{array}$ \\
\hline $\begin{array}{l}\text { Depression index (higher }=\text { less } \\
\text { depressed) }\end{array}$ & $\begin{array}{l}0.112^{* *} \\
(0.055)\end{array}$ & $\begin{array}{c}0.245^{*} \\
(0.128)\end{array}$ & $\begin{array}{l}-0.020 \\
(0.033)\end{array}$ & $\begin{array}{l}-0.047 \\
(0.078)\end{array}$ \\
\hline ADL score $(z)$ (higher = less difficulty) & $\begin{array}{l}-0.048 \\
(0.220)\end{array}$ & $\begin{array}{l}-0.169 \\
(0.492)\end{array}$ & $\begin{array}{c}0.193 \\
(0.157)\end{array}$ & $\begin{array}{c}0.412 \\
(0.387)\end{array}$ \\
\hline Walk 5 km & $\begin{array}{c}0.005 \\
(0.024)\end{array}$ & $\begin{array}{c}0.018 \\
(0.055)\end{array}$ & $\begin{array}{l}-0.023 \\
(0.018)\end{array}$ & $\begin{array}{l}-0.044 \\
(0.045)\end{array}$ \\
\hline Draw water & $\begin{array}{l}-0.003 \\
(0.020)\end{array}$ & $\begin{array}{l}-0.013 \\
(0.044)\end{array}$ & $\begin{array}{l}-0.015 \\
(0.012)\end{array}$ & $\begin{array}{l}-0.026 \\
(0.030)\end{array}$ \\
\hline Carry object & $\begin{array}{c}0.003 \\
(0.012)\end{array}$ & $\begin{array}{c}0.003 \\
(0.027)\end{array}$ & $\begin{array}{l}-0.011 \\
(0.009)\end{array}$ & $\begin{array}{l}-0.021 \\
(0.023)\end{array}$ \\
\hline Work in a field & $\begin{array}{l}-0.012 \\
(0.028)\end{array}$ & $\begin{array}{l}-0.031 \\
(0.062)\end{array}$ & $\begin{array}{l}-0.007 \\
(0.019)\end{array}$ & $\begin{array}{l}-0.007 \\
(0.045)\end{array}$ \\
\hline Climb a hill & $\begin{array}{c}0.010 \\
(0.016)\end{array}$ & $\begin{array}{c}0.003 \\
(0.037)\end{array}$ & $\begin{array}{c}-0.020^{* *} \\
(0.010)\end{array}$ & $\begin{array}{c}-0.046^{*} \\
(0.026)\end{array}$ \\
\hline
\end{tabular}

Notes: Each row gives the coefficient of a separate regression, where the outcome is regressed on a dummy for whether the village is a treatment village. The standard errors (corrected for clustering at the village level) are in parentheses below the coefficient.

*** Significant at the 1 percent level.

**Significant at the 5 percent level.

*Significant at the 10 percent level. 
The first specification is:

$$
y_{i j t}=\alpha+\beta T_{j}+\gamma T P_{t j}+\delta T_{j} * T P_{t j}+X_{i j t} \lambda+\varepsilon_{i j t},
$$

where $T_{j}$ is a dummy for whether the village was selected for the iron program, and $T P_{j t}$ is a dummy for whether the program was in operation in this block at that date (irrespective of treatment status). The coefficient of interest in this specification is $\delta$.

The second specification accounts for the pattern of take up of the program, as shown in figure 10.1 and table 10.2: we reproduce

$$
\begin{aligned}
y_{i j t}= & \alpha+\beta T_{j}+\gamma T P_{t j}+\gamma_{1} S_{1 t j}+\gamma_{2} S_{2 t j}+\delta T_{j} * T P_{t j} \\
& +\delta_{1} T_{j} * S_{1 t j}+\delta_{2} T_{j} * S_{2 t j}+X_{i j t} \lambda+\varepsilon_{i j t},
\end{aligned}
$$

where the notation is as before, and in addition, $S_{1}$ is a spline for the first six months of the program, and $S_{2}$ is a spline for the second seven months of the program. This specification will tell us if the impact on health closely follows the take up pattern.

The results of both specifications are presented in table 10.8: panel A for the entire sample, panel B for males only, and panel $\mathrm{C}$ for females only. Over its entire duration, the program does not appear to have any significant impact on self-reported health, any symptoms, or days of work, for either men or women (cutting the sample by high and low take up blocks gives very similar results).

However, the spline specification shows that "weakness", the one condition that we expect should be affected by the program, seems to follow a time pattern that corresponds closely with the evolution of the take-up of the program: the number of occurrences of weakness declines over time in the first six months after the program is introduced, and the trend is reversed afterwards. Figure 10.4 illustrates this: it is a line that represents the difference between treatment and control in a nonparametric regression of weakness on the number of days since the program started. It shows that the occurrence of the weakness symptoms initially declined, and then increased again, following the same time pattern as the take up of the program.

This pattern is similar for men and women, though it is stronger for women (recall that, by the midline, women also experienced positive effects on anemia). A similar shape is observed by women for occurrence of vomiting (note that vomiting improved, rather than worsened, as would be expected if iron had strong side effects on stomach functions) and a combined indicator for the reporting of any symptom. This suggests that the iron fortification program may indeed have improved stamina as long as it was taken up at a high rate. At the peak usage, this suggests that the rate at which people experienced weakness was 5 percentage points ( 27 percent) lower in treatment group than in control.

Even if it did improve stamina, however, the program did not increase the number of days of work, neither for men nor for women. The number of days worked was not higher during the treated period in treated villages, 


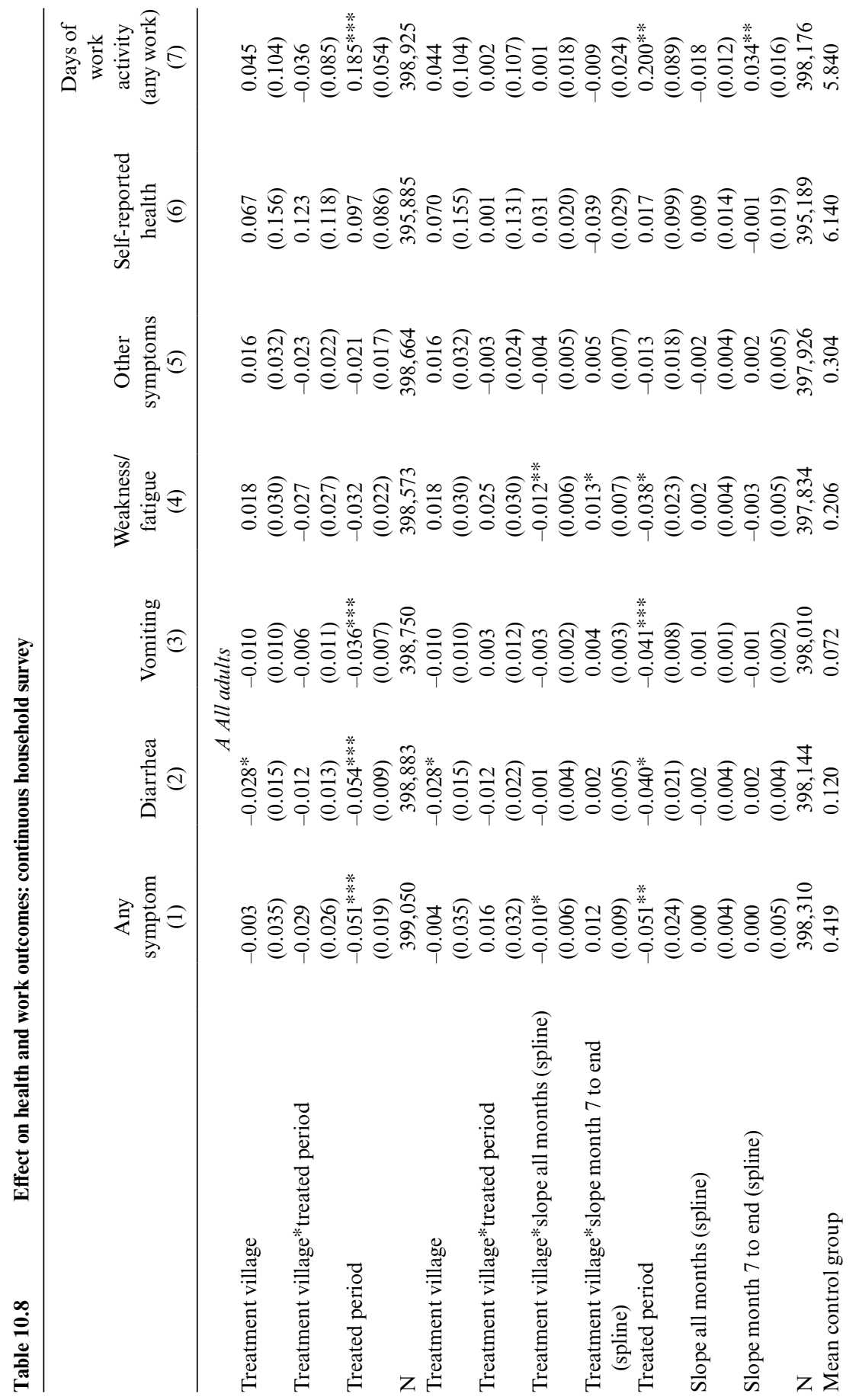




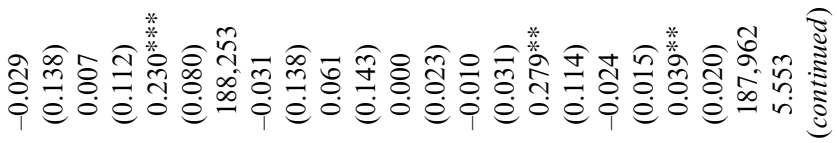

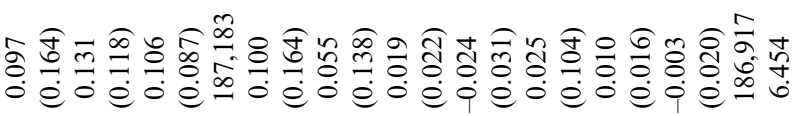

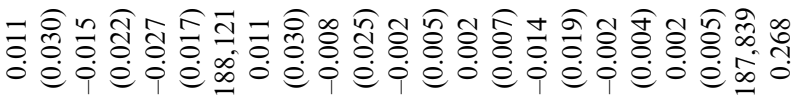

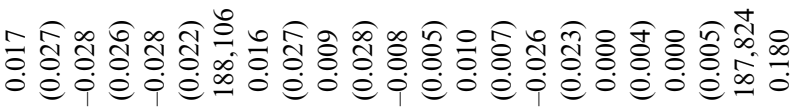

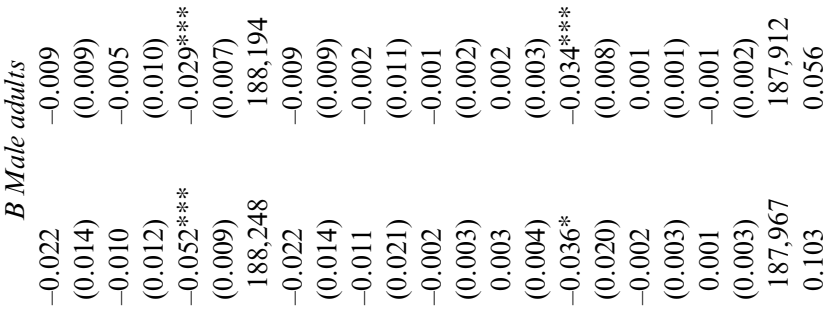

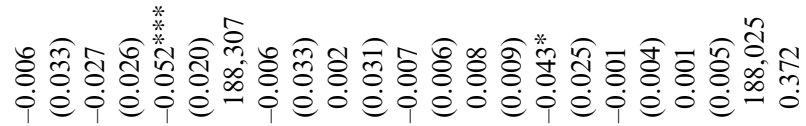

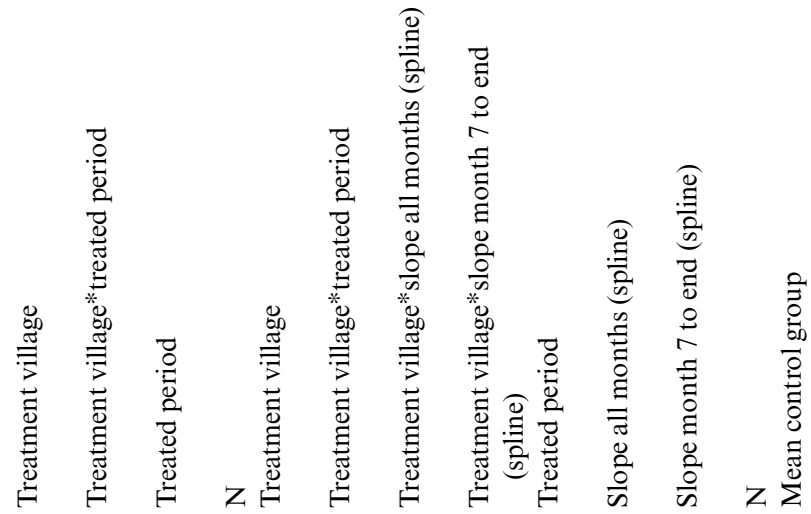




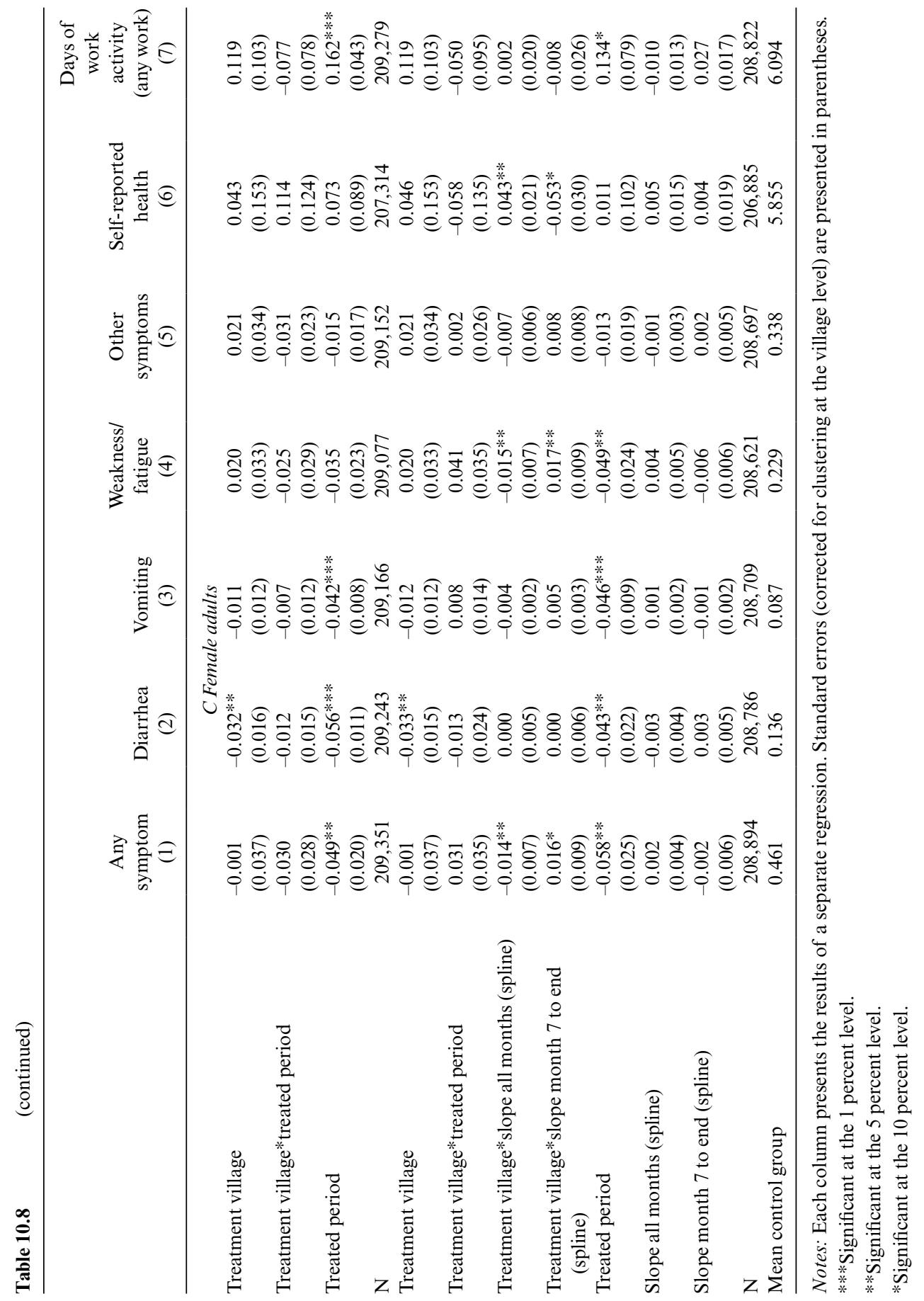




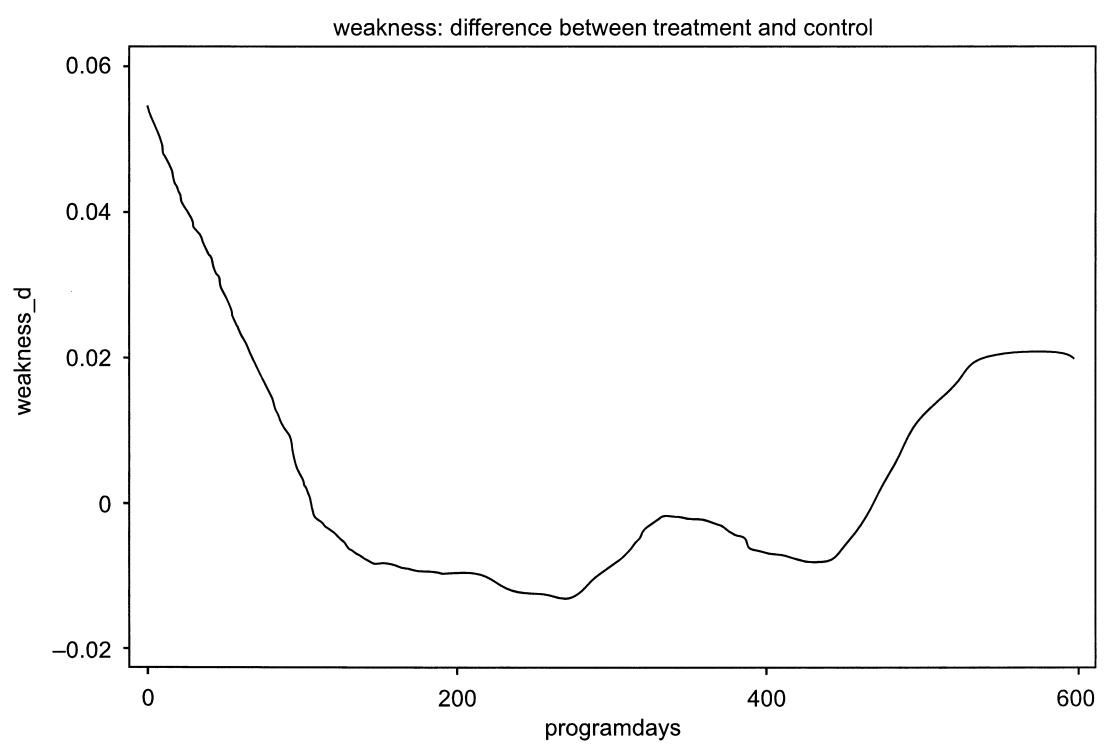

Fig. 10.4 Weakness: Difference between treatment and control

and days of work did not increase and decrease in treatment villages with the take up of the program. Thus, even though people felt less weak, they did not use this energy to work more (or the effects were too low to be detected). This lack of effect is consistent with Edgerton et al. (1979), who found very small effects of iron supplementation on productivity of tea pickers in Indonesia; and Li et al. (1994), who found small increases in output of female cotton mill workers in China. In the latter case, energy efficiency among these workers did increase significantly, but technology impeded productivity improvements at the cotton mills. It is also possible that, in this case as well, the ability to work at any given time is primarily a function of the environment (they have to be able to find work). Another possibility is that the effect would be small.

\subsection{Conclusion}

Iron deficiency anemia affects millions of people worldwide, affecting their health and productivity. While field trials have shown that iron supplementation through pills can reduce anemia, improve strength, and, in some cases, lead to increase in labor supply and productivity, the systematic distribution of iron supplementation pills to the entire population is not a practical solution. Food fortification is an alternative, but centralized fortification will leave out the poorest, who are not purchasing fortified foods.

This innovative program, developed from the ground up by an NGO, 
tried to solve this problem by introducing fortification at the local level. The program was designed to be easy and safe to implement by illiterate millers, and to not require many extra steps for the consumers (they had to agree once, and would then be considered as part of the program until they refused). Nevertheless, the program ran into a number of issues, which, taken together, reduced its effectiveness: first, despite instructions to the contrary, they switched away from the initial fortification default decision, asking the person whether they should fortify each visit; second, households did not value the program sufficiently to walk slightly further to get fortification.

These two factors combined explain why the take up of the program faltered over time. We interviewed a number of chakkis and households after the end of the program. From the point of view of the chakki, fortifying was an extra step, and since they were not paid by the quantity fortified, they chose not to take this step unless the household explicitly demanded it. Most households were happy to fortify their flour as long as the chakki did it for them, but in most cases, did not stay during the milling to check whether he was doing it. When the chakkis stopped mixing the iron, most households believed that the program must have stopped, and few bothered insisting on fortification. Ultimately, low demand from the households seems to be at the root of the decay of the program. This is despite some positive impact on symptoms of weakness in the program's initial phase, and impacts on self-reported health and happiness by the end line (which may have been placebo or reporting effects, however). It is possible that the low demand stems from the lack of any life-changing effect: the extra stamina did not allow those individuals to work more days (there may not be that much more work to be had), and it is not clear that being slightly less likely to experience weakness symptoms was enough to be convinced to do anything different than the usual.

From a policy perspective, this experience thus suggests that iron fortification may need to be even less painful for the individuals for them to take it up consistently: fortification of salt (which even poor households do purchase) seems to be a promising avenue. An alternative, which we are currently exploring in Udaipur, is to make the fortification process even easier, for example, by mixing the iron premix with the grain at the moment it is milled, thus removing the extra step. This raises the issue of whether and why such a policy is justified if households' willingness to pay for the program is so low that they will not bother to ask the chakki to do something free for them. Unlike immunization, bed nets, or TB pills, there are no obvious externalities to iron deficiency anemia, so one could argue that individuals should be left alone to deal with this problem. This question leads to a more speculative, and possibly more interesting, economic argument: individuals may have little interest in any action, however small, that brings about incremental changes to their lives, perhaps because they do not really see the point today of feeling just slightly better tomorrow (Banerjee and Mullainathan 2008). Even if the action is just to ask for a service, or to walk a little further, the simple fact to consider is that it still requires the individual to project 
themselves into this future, which is rather depressing to consider: a future where, whether with iron fortification or not, they will still be sick often and not have much work to do. This may be why people give up so easily.

Despite this, ex post, the individual would still enjoy being a little stronger, if this was just offered to him. This underscores the importance of the status quo, or default (Madrian and Shea 2001; Choi et al.; Rabin and Thaler; Kahneman, Knetsch, and Thaler 1991). This program was meant to be in part a "default" program, but this would have relied on the cooperation of the chakkis, who prefer, like everyone, to do a little less extra work. Selling fortified salt in PDS would address this issue, but the question that will arise is the following: should the only double fortified salt be available? This would curtail the individual's freedom (some people may not want to get their salt fortified), but having both kinds of salt reintroduces a choice. Perhaps the best option is to have both types available, but to sell the double fortified salt at a small discount over the regular price. Take up may then be high, since comparing prices and taking the cheaper good is easy to do and to justify to oneself without considering the future.

\section{Appendix}

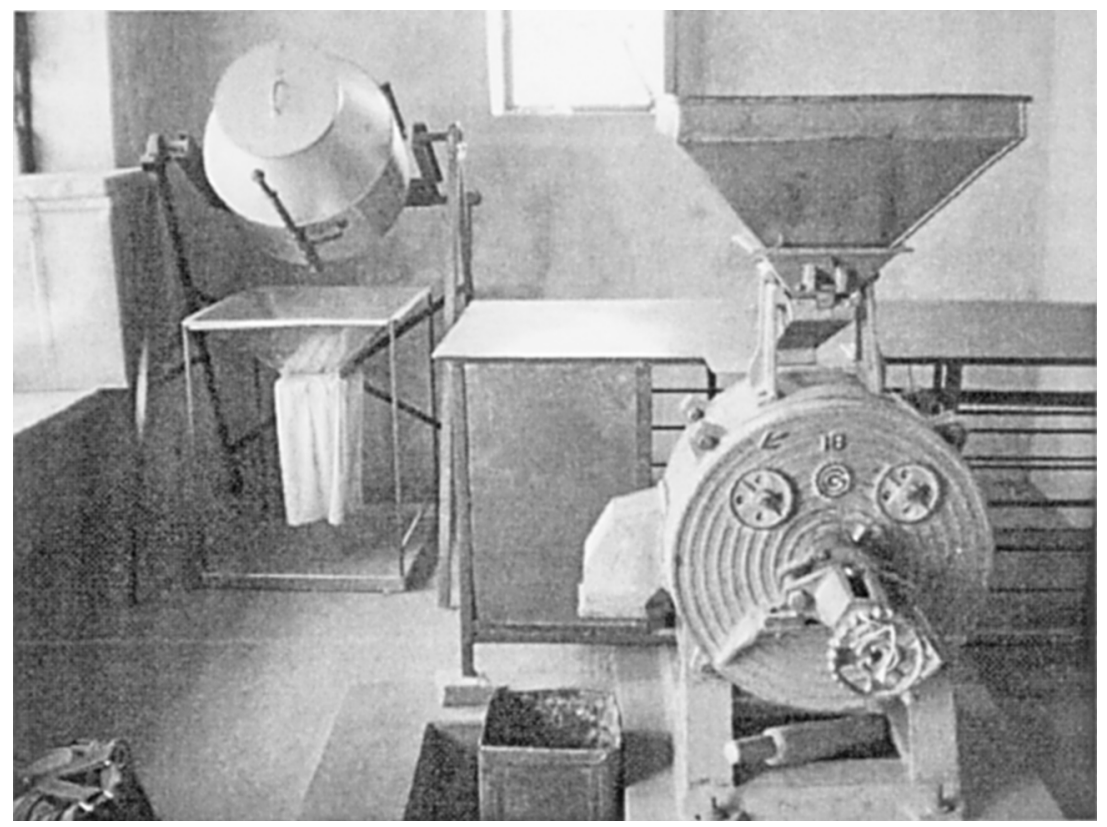

Fig. 10A.1 The fortification machine is on the left, and the milling machine is on the right 


\section{References}

Banerjee, A., A. Deaton, and E. Duflo. 2004. Wealth, health, and health services in rural Rajasthan. Poverty Action Lab Paper no. 8, May.

Banerjee, A., and S. Mullainathan. 2008. Limited attention and income distribution. American Economic Review 98 (2): 489-93.

Basta, S., S. Soekirman, D. Karyadi, and N. Scrimshaw. 1979. Iron deficiency anemia and the productivity of adult males in Indonesia. American Journal of Clinical Nutrition 32 (4): 916-25.

Choi, J. J., D. Laibson, B. C. Madrian, and A. Metrick. 2002. Defined contribution pensions: Plan rules, participant decisions, and the path of least resistance. In Tax policy and the economy, ed. J. M. Poterba, 67-114. Cambridge, MA: MIT Press.

Edgerton, V., G. Gardner, Y. Ohira, K. Gunawardena, and B. Senewiratne. 1979. Iron-deficiency and its effect on worker productivity and activity patterns. British Medical Journal 2:1546-9.

Haas, J., and T. Brownlie. 2001. Iron deficiency and reduced work capacity: A critical review of the research to determine a causal relationship. Journal of Nutrition (Supplement) 131: 676S-88S.

Kahneman, D., J. Knetsch, and R. Thaler. 1991. Anomalies: The endowment effect, loss aversion, and status quo bias. Journal of Economic Perspectives 5 (1): 193-206.

Li, R., X. Chen, H. Yan, P. Deurenberg, L. Garby, and J. Hautvast. 1994. Functional consequences of iron supplementation in iron-deficient female cotton workers in Beijing China. American Journal of Clinical Nutrition 59:908-13.

Madrian, B., and D. Shea. 2001. The power of suggestion: Inertia in 401(k) participation and savings behavior. The Quarterly Journal of Economics 116 (4): $1149-87$.

Micronutrient Initiative. 2007. Building the capacity of small millers: Training manual developed, September. Available at http://www.micronutrient.org/CMFiles/News $\% 20$ Room/Announcements/Training-Manual-Capacity-Building-Small-MillersKL-_2_.pdf.

. 2008. Micronutrient Initiative: Five year strategic plan. Available at http:// www.micronutrient.org/CMFiles/News\%20Room/Announcements/MI-Strat Plan-08-13.pdf.

Rabin, M., and R. H. Thaler. 2001. Anomalies: Risk aversion. Journal of Economic Perspectives 15 (1): 219-32.

Stolfzfus, R. 2001. Iron-deficiency anaemia: Reexamining the nature and magnitude of the public health problem. Summary: Implications for research and programs. Journal of Nutrition 131 (Suppl. 2): 697S-701S.

Thomas, D., E. Frankenberg, J. Friedman, J. Habicht, M. Hakimi, N. Jones, C. McKelvey, et al. 2003. Iron deficiency and the well-being of older adults: Early results from a randomized nutrition intervention. Paper presented at the Population Association of America Annual Meetings. April, Minneapolis, MN.

World Health Organization (WHO)/UNICEF/UNU. 2001. Iron deficiency anaemia: Assessment, prevention, and control. Geneva, WHO. Available at: http://www.who .int/nut/documents/ida_assessment_prevention_control.pdf. 